\title{
Assessment of Quality of Life With 5 Different Scales in Patients Participating in Comprehensive Cardiac Rehabilitation After Acute Myocardial Infarction
}

\author{
Shoji Suzuki, MD; Hiroshi Takaki, MD; Yoshio Yasumura, MD; Satoru Sakuragi, MD; \\ Shuichi Takagi, MD; Yoshiaki Tsutsumi, MD; Naohiko Aihara, MD; \\ Fumio Sakamaki, MD; Yoichi Goto, MD
}

\begin{abstract}
Background Measures assessing quality of life (QOL) in patients participating in comprehensive cardiac rehabilitation (CCR) have not been established in Japan.

Methods and Results To compare different types of QOL scales and to determine the impact of CCR on QOL in Japanese cardiac patients, 5 different types of questionnaires were assessed in 44 patients participating in CCR after acute myocardial infarction (AMI). After 3-month CCR, peak oxygen uptake ( $\left.\mathrm{PV} \dot{\mathrm{O}}_{2}, \mathrm{p}<0.01\right)$, Sickness Impact Profile (SIP) total score $(\mathrm{p}<0.05)$ and physical function-related QOL scores (Specific Activity Scale (SAS), $\mathrm{p}<0.01$; SIP physical score, $\mathrm{p}<0.01$ ) significantly improved, whereas psychosocial/mental aspect-related QOL scores (Ministry of Health and Welfare (MHW)-QOL score, SIP psychosocial score, State-Trait Anxiety Inventory, Self-rating Depression Scale) did not change on the average. However, patients with low $\mathrm{PV}_{2}$ $\left(<21.7 \mathrm{ml} \cdot \mathrm{min}^{-1} \cdot \mathrm{kg}^{-1}\right)$ showed significant improvements in all scores after CCR, whereas patients with preserved exercise capacity showed improvements only in physical function-related scores (SAS and physical SIP). Furthermore, patients with anxiety and depression showed significant improvements in these respective measures after CCR.

Conclusion In patients with AMI, physical function-related QOL scores improve after a 3-month CCR program, but psychosocial/mental aspect-related QOL scores improve only in those with impaired exercise tolerance or anxiety/depression. Thus, changes in QOL after CCR depend on type of QOL scale used and the baseline status of the patient. In addition, in Japanese cardiac patients MHW-QOL mainly reflects psychosocial/mental aspect-related QOL, as well as overall QOL. (Circ J 2005; 69: 1527-1534)
\end{abstract}

Key Words: Acute myocardial infarction; Cardiac rehabilitation; Depression; Psychological wellbeing; Quality of life

C omprehensive cardiac rehabilitation (CCR) improves psychological well-being or quality of life (QOL) in patients after acute myocardial infarction (AMI),-4 but because the various QOL scales assess the physical and psychological aspects of QOL differently, it is not fully understood which aspect of QOL is improved by CCR. In addition, it remains unclear which patient group benefits most from CCR in terms of QOL. Furthermore, because most QOL instruments, except for the QOL score of the Ministry of Health and Welfare in Japan (MHW-QOL),6,6 were devised in Western countries, their features have not been comparably determined in Japanese cardiac patients. In fact, conflicting results have been reported on the effect of CCR on the MHW-QOL score in Japanese patients after AMI; Yoshida et al reported a significant improvement in the MHW-QOL score, whereas Fujiwara et al reported no significant change?

The effect of CCR on the different aspects of QOL in Japanese patients after AMI using multiple QOL instru-

(Received May 2, 2005; revised manuscript received September 29, 2005; accepted October 6, 2005)

Division of Cardiology, National Cardiovascular Center, Suita, Japan

Mailing address: Yoichi Goto, MD, Division of Cardiology, National Cardiovascular Center, 5-7-1 Fujishiro-dai, Suita 565-8565, Japan.

E-mail: ygoto@hsp.ncvc.go.jp ments has not been intensively assessed. Accordingly, the purpose of the present study was to use multiple QOL instruments to assess Japanese patients after AMI, to determine the comparative features of the various QOL scales, including the MHW-QOL score, and to clarify the characteristics of the patients who are likely to benefit most from CCR in terms of QOL.

\section{Methods}

\section{Subjects}

We studied 44 patients who had experienced an AMI (mean age: $58 \pm 9$ years, range $45-78$, male/female: $37 / 7$ ) and who participated in CCR with exercise training program. All patients gave written informed consent.

The diagnosis of AMI was confirmed by electrocardiographic changes and serum creatine kinase (CK) elevation. Peak serum CK was 3,255 $\pm 2,588$ U/L. Seven patients $(16 \%)$ had had a prior myocardial infarction and 2 patients $(5 \%)$ had congestive heart failure (Killip's class $\geq 2$ ) on admission. All patients underwent cardiac catheterization: 38 patients $(86 \%)$ had successful percutaneous coronary intervention (PCI), 2 patients $(5 \%)$ underwent coronary artery bypass grafting $(\mathrm{CABG})$ and 5 patients $(11 \%)$ with residual myocardial ischemia were medically controlled. Mean left ventricular ejection fraction (LVEF) was $45 \pm 8 \%$ 
by left ventriculography 3-4 weeks after the onset of AMI.

\section{Cardiac Rehabilitation Program}

The CCR program consisted of exercise training of moderate intensity and education for 3 months, as previously described?-10 Patients who did not have angina or ischemic changes on ECG at a low level of exercise (200-500 m walking test) were enrolled in the exercise training approximately 10-15 days after AMI. Patients with uncontrolled heart failure and/or angina, multiple organ disorders such as serum creatinine $\geq 2.0 \mathrm{mg} / \mathrm{ml}$, serum transaminase $\geq 40 \mathrm{IU} / \mathrm{ml}$, inflammatory disease or embolic disorders were excluded. The exercise program consisted of walking, bicycling on an ergometer, and aerobic dance sessions of 50-80 min, 3-5 times each week for 3 months. Exercise intensity was determined individually at $50-60 \%$ of heart rate reserve (Karvonen's equation, $\mathrm{k}=0.5-0.6)^{11,12}$ obtained by maximal symptom-limited cardiopulmonary exercise testing (CPX) or at level 13 ("a little hard") of the 6-20 scale perceived rating of exercise (original Borg's score) $!^{3}$ The exercise program started with supervised sessions for 2 weeks, followed by home exercise combined with once or twice weekly supervised sessions for the remaining 10 weeks. Home exercise consisted mainly of brisk walking at a prescribed heart rate for 30-60 min 3-5 times per week. There were no adverse cardiac events such as death, AMI, unplanned PCI or $\mathrm{CABG}$, or worsening of heart failure during the 3-month CCR.

Patients were encouraged to attend the education classes, which were held 3 times each week with lectures on coronary artery disease, secondary prevention, diet, smoking cessation, medication, and home exercise given by physicians, nurses, dieticians, pharmacists and exercise instructors. In addition, all patients received individual counseling on exercise prescription, secondary prevention, and daily life activities by a physician and a CCR nurse at the time of hospital discharge and at the end of the CCR program.

\section{$C P X$}

A symptom-limited CPX was performed at the beginning and end of the 3-month CCR! 14 After a 2 min rest on the bicycle ergometer (Examiner, Lode B.V. GroningenHolland), patients started pedaling at an intensity of $0 \mathrm{~W}$ for $1 \mathrm{~min}$ (warm-up), then performed an incremental exercise test with a ramp protocol ( $15 \mathrm{~W} / \mathrm{min})$ until exhaustion. During exercise testing, breathed gas was continuously collected to measure oxygen uptake $\left(\dot{\mathrm{V}}_{2}\right)$ and carbon dioxide production $\left(\dot{\mathrm{V}}_{\mathrm{CO}} 2\right)$ with a gas analyzer AE280 (Minato Medical Electronics, Osaka, Japan). Blood pressure was measured every minute and a 12-lead ECG was continuously monitored during exercise. Patients who showed angina or ischemic ECG changes at the initial exercise test were excluded.

Peak oxygen uptake $\left(\mathrm{PV}_{2}\right)$ was defined as the highest $\dot{\mathrm{V}} \mathrm{O}_{2}$ value achieved at peak exercise after reaching the respiratory compensation point. The $\dot{\mathrm{V}} \mathrm{O}_{2}$ value at the anaerobic threshold (AT) or ventilatory threshold was determined as the point at which $\dot{\mathrm{VCO}}_{2}$ increased in a nonlinear fashion relative to the rate of $\dot{\mathrm{V}} \mathrm{O}_{2}$, according to the time trend of the ratio of minute ventilation $\left(\dot{\mathrm{V}}_{\mathrm{E}}\right)$ and $\dot{\mathrm{V}}_{2}\left(\dot{\mathrm{V}}_{\mathrm{E}} / \dot{\mathrm{V}}_{2}\right)$, an abrupt increase in the respiratory exchange ratio, or the Vslope method! 15,16

\section{QOL Questionnaires}

At the beginning and end of the 3-month CCR program, all patients answered the 5 types of questionnaires assessing QOL: Specific Activity Scale (SAS), Sickness Impact Profile (SIP), MHW-QOL, State-Trait Anxiety Inventory (STAI) and Self-rating Depression Scale (SDS). SAS is a scale of functional capacity related to daily activities expressed by metabolic equivalents, ${ }^{17,18}$ and SIP comprises 136 items including 12 domains to assess patient behaviors, such as physical disorders (ambulation, mobility, body care and movement), psychosocial disorders (social interaction, alertness behavior, emotional behavior, communication) and other disorders (sleep and rest, eating, work, home management, recreation and pastimes), expressed by the percentage of acquired scores.19,20 It has been successfully used in the field of CCR ${ }^{20-22}$ MHW-QOL has both generic and disease-related scales and mainly assesses the psychosocial and mental aspects of QOL ${ }^{5-7}$ It comprises 39 items, including 3 domains ( 2 generic domains and 1 disease-specific domain) for subjective evaluation of health (8 items), social attitude and subjective wellbeing (21 items), and disease-specific conditions (10 items). In the present study we used a total score for the 39 items (so-called "broad sense score") as the MHW-QOL score. STAI is a scale of anxiety and comprises 2 domains of state-anxiety and trait-anxiety, the former representing an anxiety state that a patient faces and the latter mainly representing an anxious personality. Each domain comprises 20 items with 4-point scales. ${ }^{23}$ SDS evaluates depression by 20 items with 4-point scales 24 A state of anxiety and/or depression was judged when the percent score of STAI and/or SDS was above $50 \%$. Higher scores indicate a more favorable QOL trait in SAS and MHW-QOL, whereas lower scores indicate a more favorable QOL trait in SIP, STAI and SDS.

\section{Data Analysis}

Data were analyzed in 3 steps. First, data for exercise capacity and QOL were compared between the 2 time points (ie, before and after the 3-month CCR) in the whole group of patients. Second, to assess the influence of baseline exercise capacity on the improvement in QOL scores after CCR, QOL data were compared between the 2 time points in the subgroups of preserved and impaired exercise capacity. Because the average $\mathrm{PV}_{2}$ measured by $\mathrm{CPX}$ at the beginning of the CCR was $21.7 \pm 1.7 \mathrm{ml} \cdot \mathrm{min}^{-1} \cdot \mathrm{kg}^{-1}$, patients were divided into 2 groups according to their initial $\mathrm{PV}_{2}$ value: Low $\mathrm{PV}_{2}$ group $\left(\mathrm{PVO}_{2}<21.7 \mathrm{ml} \cdot \mathrm{min}^{-1} \cdot \mathrm{kg}^{-1}\right.$, $\mathrm{n}=22)$ and Preserved $\mathrm{P}_{\mathrm{V} O} \mathrm{O}_{2}$ group $\left(\mathrm{PVO}_{2} \geq 21.7 \mathrm{ml} \cdot \mathrm{min}^{-1}\right.$. $\mathrm{kg}^{-1}, \mathrm{n}=22$ ). Finally, QOL data were compared between the 2 time points in the subgroups with and without initial anxiety (STAI score $\geq 50 \%$ or $<50 \%$, respectively) and with and without initial depression (SDS score $\geq 50 \%$ or $<50 \%$, respectively).

\section{Statistical Analysis}

All values are expressed as mean $\pm \mathrm{SD}$. The paired t-test was used to compare paired variables before and after CCR within a group. Comparisons between groups were made by unpaired t-test. Statistical analysis was performed using StatView software (Abacus, Cupertino, CA, USA). A pvalue less than 0.05 was considered statistically significant.

\section{Results}

Changes in Exercise Capacity and QOL Scores in the Whole Group

As shown in Table 1, which summarizes the baseline 
Table 1 Characteristics of $\mathbf{4 4}$ Patients After Acute Myocardial Infarction

\begin{tabular}{|c|c|c|c|c|}
\hline & $\begin{array}{l}\text { Total } \\
(n=44)\end{array}$ & $\begin{array}{c}\text { Preserved } \mathrm{PV}_{2} \text { group } \\
(n=22)\end{array}$ & $\begin{array}{c}\text { Low } \mathrm{P}_{(} \dot{V} \mathrm{O}_{2} \text { group } \\
(n=22)\end{array}$ & $p$ value \\
\hline Age (years) & $58 \pm 10$ & $57 \pm 11$ & $59 \pm 9$ & NS \\
\hline $\operatorname{Sex}(M / F)$ & $37 / 7$ & $20 / 2$ & $17 / 5$ & $N S$ \\
\hline Hypertension & $21(48 \%)$ & $12(55 \%)$ & $9(41 \%)$ & NS \\
\hline Hyperlipidemia & $18(41 \%)$ & $10(45 \%)$ & $8(36 \%)$ & NS \\
\hline Diabetes mellitus & $12(27 \%)$ & $6(27 \%)$ & $6(27 \%)$ & $N S$ \\
\hline Obesity $\left(B M I \geq 26 \mathrm{~kg} / \mathrm{m}^{2}\right)$ & $10(23 \%)$ & $4(18 \%)$ & $6(27 \%)$ & $N S$ \\
\hline Smoking & $23(52 \%)$ & $14(64 \%)$ & $9(41 \%)$ & NS \\
\hline Family history & $9(20 \%)$ & $4(18 \%)$ & $5(23 \%)$ & $N S$ \\
\hline Killip class $\geq 2$ (numbers) & 2 & 0 & 2 & NS \\
\hline PCI/CABG/none & $38 / 2 / 5$ & $18 / 1 / 3$ & $20 / 1 / 2$ & NS \\
\hline peak $C K(I U / m l)$ & $3,255 \pm 2,588$ & $3,009 \pm 1,986$ & $3,384 \pm 2,796$ & NS \\
\hline $\operatorname{LVEF}(\%)$ & $44.5 \pm 8.2$ & $45.9 \pm 6.6$ & $42.9 \pm 9.6$ & $<0.05$ \\
\hline$P \dot{V} \mathrm{O}_{2}\left(\mathrm{ml} \cdot \mathrm{kg}^{-1} \cdot \mathrm{min}^{-1}\right)$ & $21.7 \pm 4.9$ & $24.7 \pm 3.6$ & $18.1 \pm 3.8$ & $<0.001$ \\
\hline
\end{tabular}

Values are mean $\pm S D$. $P$ values for comparisons between Preserved $P \dot{V} \mathrm{O}_{2}$ and Low $\mathrm{PV} \mathrm{O}_{2}$ groups.

$\mathrm{P} \dot{V} \mathrm{O}_{2}$, peak oxygen uptake; Preserved $\mathrm{P} \dot{V} \mathrm{O}_{2}$ group, patients whose baseline $\mathrm{P} \dot{V} \mathrm{O}_{2}$ values were equal to or above average $\left(\mathrm{P} \dot{V} \mathrm{O}_{2}\right.$ $\left.\geq 21.7 \mathrm{ml} \cdot \mathrm{kg}^{-1} \cdot \mathrm{min}^{-1}\right)$; Low $P \dot{V} \mathrm{O}_{2}$ group, patients whose baseline $P \dot{\mathrm{V}} \mathrm{O}_{2}$ value were below average $\left(\mathrm{P \dot {V }} \mathrm{O}_{2}<21.7 \mathrm{ml} \cdot \mathrm{kg}^{-1} \cdot \mathrm{min}^{-1}\right)$; $B M I$, body mass index; PCI, percutaneous coronary intervention; $C A B G$, coronary artery bypass grafting; $C K$, serum concentration of creatine kinase; LVEF, left ventricular ejection fraction.

Table 2 Exercise Capacity and QOL Scores Before and After Comprehensive Cardiac Rehabilitation in All Patients

\begin{tabular}{|c|c|c|c|}
\hline & Before $C C R$ & After CCR & $p$ value \\
\hline Peak $R$ & $1.26 \pm 0.12$ & $1.24 \pm 1.0$ & $N S$ \\
\hline$P \dot{V} \mathrm{O}_{2}\left(\mathrm{ml} \cdot \mathrm{kg}^{-1} \cdot \mathrm{min}^{-1}\right)$ & $21.7 \pm 1.7$ & $24.7 \pm 2.6$ & $<0.01$ \\
\hline$\dot{V} O_{2}$ at $A T\left(\mathrm{ml} \cdot \mathrm{kg}^{-1} \cdot \mathrm{min}^{-1}\right)$ & $11.8 \pm 2.3$ & $13.1 \pm 2.5$ & $<0.01$ \\
\hline SAS $(M E T S)$ & $4.5 \pm 1.7$ & $5.3 \pm 0.7$ & $<0.05$ \\
\hline \multicolumn{4}{|l|}{ SIP (\% scores) } \\
\hline Total & $7.9 \pm 5.6$ & $5.5 \pm 4.9$ & $<0.05$ \\
\hline Physical disorders & $7.2 \pm 3.1$ & $1.5 \pm 1.6$ & $<0.01$ \\
\hline Psychosocial disorders & $6.0 \pm 4.4$ & $5.8 \pm 7.4$ & $N S$ \\
\hline Other disorders & $11.5 \pm 7.5$ & $10.6 \pm 8.4$ & $N S$ \\
\hline$M H W-Q O L$ (scores) & $57.4 \pm 12.7$ & $58.6 \pm 20.5$ & $N S$ \\
\hline \multicolumn{4}{|l|}{ STAI (\% scores) } \\
\hline Total & $49.3 \pm 10.9$ & $46.9 \pm 13.2$ & $N S$ \\
\hline State-anxiety & $48.2 \pm 11.7$ & $45.3 \pm 12.2$ & NS \\
\hline Trait-anxiety & $49.7 \pm 12.0$ & $47.1 \pm 12.3$ & NS \\
\hline SDS (\% scores $)$ & $45.3 \pm 9.5$ & $43.4 \pm 7.9$ & $N S$ \\
\hline
\end{tabular}

Values are mean $\pm S D$

$Q O L$, quality of life; $\mathrm{CCR}$, comprehensive cardiac rehabilitation; Peak $\mathrm{R}$, respiratory exchange ratio at peak exercise; $\mathrm{P} \dot{V} \mathrm{O}_{2}$, peak oxygen uptake; AT, anaerobic threshold (or ventilatory threshold); SAS, specific activity scale; METs, metabolic equivalents; SIP, sickness impact profile; $M H W-Q O L, Q O L$ score of the Ministry of Health and Welfare in Japan; STAI, state-trait anxiety inventory; SDS, self-rating depression scale.

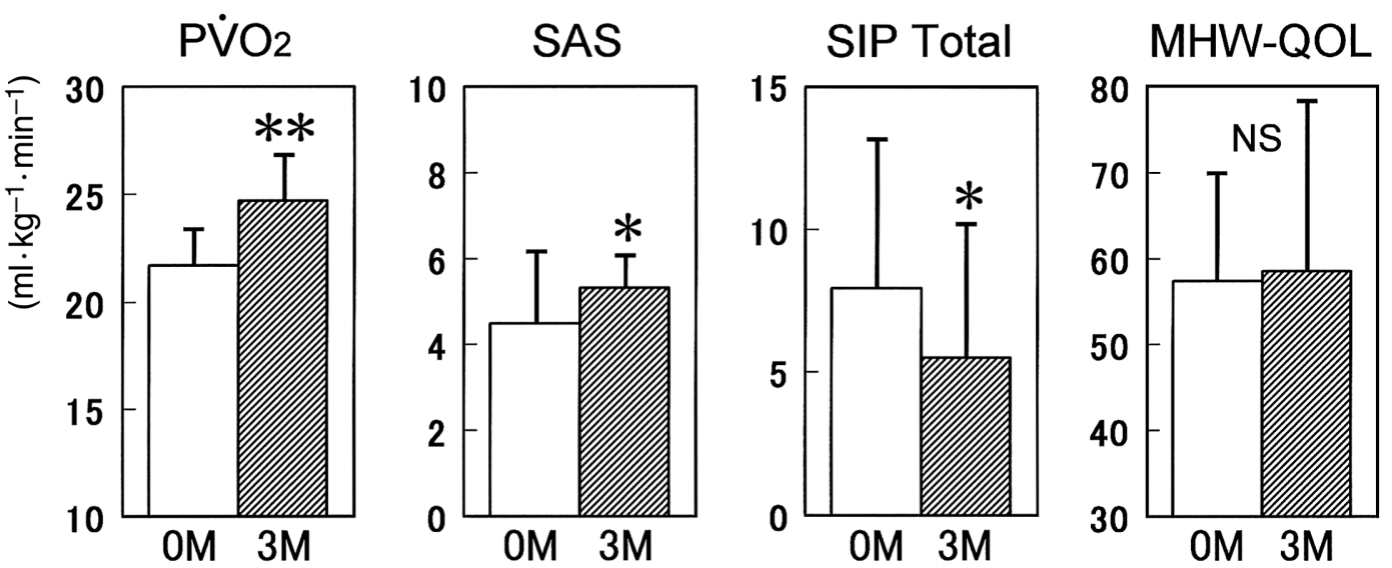

Fig 1. Comparisons of exercise capacity and quality of life (QOL) scores before and after 3-month comprehensive cardiac rehabilitation (CCR) in all 44 patients. $\mathrm{PV} \dot{\mathrm{O}}_{2}$, peak oxygen uptake; SAS, Specific Activity Scale; SIP total, Sickness Impact Profile total score; MHW-QOL, Ministry of Health and Welfare QOL broad sense score: OM, baseline values (before CCR); $3 \mathrm{M}$, values after 3-month CCR program. $* \mathrm{p}<0.05$ and $* * \mathrm{p}<0.01$ compared with baseline values. 
Table 3 Exercise Tolerance and QOL Related Scores Change in Subgroups

\begin{tabular}{|c|c|c|c|c|c|c|}
\hline & \multicolumn{3}{|c|}{ Preserved $\mathrm{P}^{\circ} \mathrm{O}_{2}$ group $(n=22)$} & \multicolumn{3}{|c|}{ Low $\mathrm{PV}_{2}$ group $(n=22)$} \\
\hline & Before CCR & After CCR & $p$ value $e^{\#}$ & Before $C C R$ & After CCR & $p$ value $^{\#}$ \\
\hline$P \dot{V} \mathrm{O}_{2}\left(\mathrm{ml} \cdot \mathrm{kg}^{-1} \cdot \mathrm{min}^{-1}\right)$ & $24.7 \pm 3.6$ & $27.5 \pm 5.0$ & $<0.01$ & $18.1 \pm 3.8 * *$ & $21.3 \pm 5.4 * *$ & $<0.01$ \\
\hline$\dot{V} \mathrm{O}_{2}$ at $\mathrm{AT}\left(\mathrm{ml} \cdot \mathrm{kg}^{-1} \cdot \mathrm{min}^{-1}\right)$ & $13.2 \pm 1.8$ & $14.5 \pm 2.3$ & 0.05 & $10.2 \pm 1.7$ & $11.6 \pm 1.8$ & $<0.05$ \\
\hline SAS (METS) & $5.0 \pm 1.7$ & $5.6 \pm 1.9$ & $<0.05$ & $3.9 \pm 1.5^{*}$ & $4.9 \pm 1.3$ & $<0.05$ \\
\hline \multicolumn{7}{|l|}{ SIP (\% scores) } \\
\hline Total & $7.7 \pm 5.8$ & $6.0 \pm 4.8$ & $<0.05$ & $8.1 \pm 5.6$ & $4.1 \pm 5.2$ & $<0.05$ \\
\hline Physical disorders & $6.9 \pm 7.9$ & $0.8 \pm 1.7$ & $<0.01$ & $6.8 \pm 5.8$ & $2.1 \pm 3.4$ & $<0.01$ \\
\hline Psychosocial disorders & $6.2 \pm 6.9$ & $6.6 \pm 7.6$ & $N S$ & $4.8 \pm 5.5$ & $2.7 \pm 5.6$ & $<0.05$ \\
\hline Other disorders & $10.5 \pm 6.2$ & $10.6 \pm 8.1$ & NS & $12.7 \pm 8.8$ & $8.6 \pm 7.9$ & $<0.05$ \\
\hline MHW-QOL (scores) & $61.0 \pm 8.1$ & $60.3 \pm 10.8$ & NS & $53.1 \pm 10.0^{* *}$ & $56.6 \pm 9.3$ & $<0.05$ \\
\hline \multicolumn{7}{|l|}{ STAI (\% scores) } \\
\hline Total & $47.7 \pm 10.1$ & $47.9 \pm 15.3$ & NS & $51.2 \pm 11.8$ & $45.7 \pm 10.3$ & $<0.05$ \\
\hline State-anxiety & $47.9 \pm 10.3$ & $47.6 \pm 17.0$ & NS & $49.6 \pm 13.2$ & $44.4 \pm 10.3$ & $<0.05$ \\
\hline Trait-anxiety & $47.6 \pm 11.1$ & $48.3 \pm 14.7$ & NS & $52.7 \pm 12.6$ & $46.9 \pm 11.2$ & $<0.05$ \\
\hline SDS (\% scores) & $42.3 \pm 7.0$ & $43.6 \pm 10.7$ & NS & $49.2 \pm 10.5 *$ & $44.4 \pm 6.7$ & $<0.05$ \\
\hline
\end{tabular}

Values are mean $\pm S D$.

${ }^{\#}$ Comparisons were made by paired $t$-test before and after CCR within the group; ${ }^{*} p<0.05, * * p<0.01$ compared with corresponding values in the Preserved $\mathrm{P} \dot{V} \mathrm{O}_{2}$ group.

Abbreviations as in Table 2.
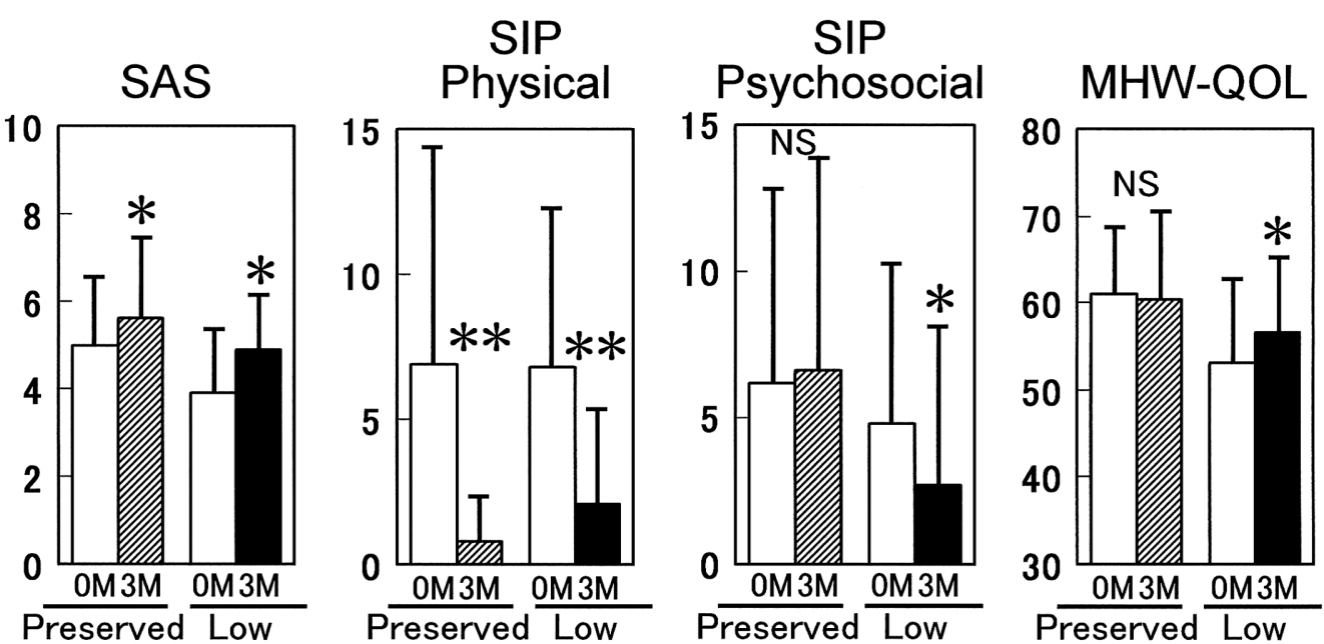

Fig 2. Changes in representative quality of life (QOL) scores before and after 3-month comprehensive cardiac rehabilitation program in patients with preserved and impaired exercise capacity. Patients with preserved exercise capacity showed improvements in Specific Activity Scale (SAS) and Sickness Impact Profile (SIP) physical score, but not in SIP psychosocial and Ministry of Health and Welfare (MHW)-QOL scores, whereas patients with impaired exercise capacity showed improvements in all 4 scores. SIP physical, SIP physical disorder score; SIP psychosocial, SIP psychosocial disorder score; Preserved, preserved exercise capacity group (peak $\dot{\mathrm{VO}}_{2} \geq 21.7 \mathrm{ml} \cdot \mathrm{min}^{-1} \cdot \mathrm{kg}^{-1}$ ); Low, impaired exercise capacity group (peak $\dot{\mathrm{V}} 2<21.7 \mathrm{ml} \cdot \mathrm{min}^{-1} \cdot \mathrm{kg}^{-1}$ ). $* \mathrm{p}<0.05$ and $* * \mathrm{p}<0.01$ compared with baseline values.

clinical characteristics of the 2 groups with preserved and impaired exercise capacity, there were no significant differences except for $\mathrm{LVEF}$ and $\mathrm{PVO}_{2}$. Table 2 and Fig 1 summarize the data for exercise capacity and QOL scores before and after the 3-month CCR. The respiratory exchange ratio at peak exercise was sufficiently high both before and after CCR, suggesting that the measured $\mathrm{PVO}_{2}$ values are reliable. After 3 months of CCR, $\mathrm{PVO}_{2}(+13.8 \%$, $\mathrm{p}<0.01), \dot{\mathrm{V} O} 2$ at AT $(+11.0 \%, \mathrm{p}<0.01)$ and SIP total score $(-30.4 \%, \mathrm{p}<0.05)$ improved significantly, as did the SAS $(+17.8 \%, \mathrm{p}<0.05)$ and SIP physical disorder score $(-79.2 \%$, $\mathrm{p}<0.01$ ), both representing QOL related to physical function. However, other QOL scores such as the SIP score for psychosocial disorders and other disorders, MHW-QOL, STAI and SDS, all representing QOL related to psychosocial or mental function, did not change after 3 months of CCR.
Changes in QOL Scores in the Subgroups With Preserved and Impaired Exercise Capacity (Table 3, Fig 2)

In the Preserved $\mathrm{PVO}_{2}$ group, $\mathrm{PV}_{2}(+11.3 \%, \mathrm{p}<0.01)$, $\dot{\mathrm{VO}}_{2}$ at AT $(+9.8 \%, \mathrm{p}=0.05)$, SIP total score $(-22.1 \%, \mathrm{p}<$ $0.05)$, and physical function-related QOL scores (ie, SAS $(+12.0 \%, \mathrm{p}<0.05)$ and SIP physical disorder score $(-88.4 \%$, $\mathrm{p}<0.01$ ), significantly improved after $\mathrm{CCR}$, but there was no significant change in the psychosocial and mental aspectrelated QOL scores (ie, SIP psychosocial disorder score, SIP other disorder score, MHW-QOL, STAI, and SDS). In contrast, the Low $\mathrm{PV}_{2}$ group showed significant improvements in $\mathrm{PVO}_{2}(+17.7 \%, \mathrm{p}<0.01), \dot{\mathrm{VO}} 2$ at $\mathrm{AT}(+13.7 \%, \mathrm{p}<$ $0.05)$, SIP total score $(-49.4 \%, \mathrm{p}<0.05)$, and both physical function-related QOL (SAS $+25.6 \%, \mathrm{p}<0.05$; SIP physical disorder score $-69.1 \%, \mathrm{p}<0.01)$ and $\mathrm{psychosocial} /$ mental aspect-related QOL scores after CCR (SIP psychosocial disorder score $-43.8 \%, \mathrm{p}<0.05$; MHW-QOL +6.7\%, $\mathrm{p}<0.05$; 

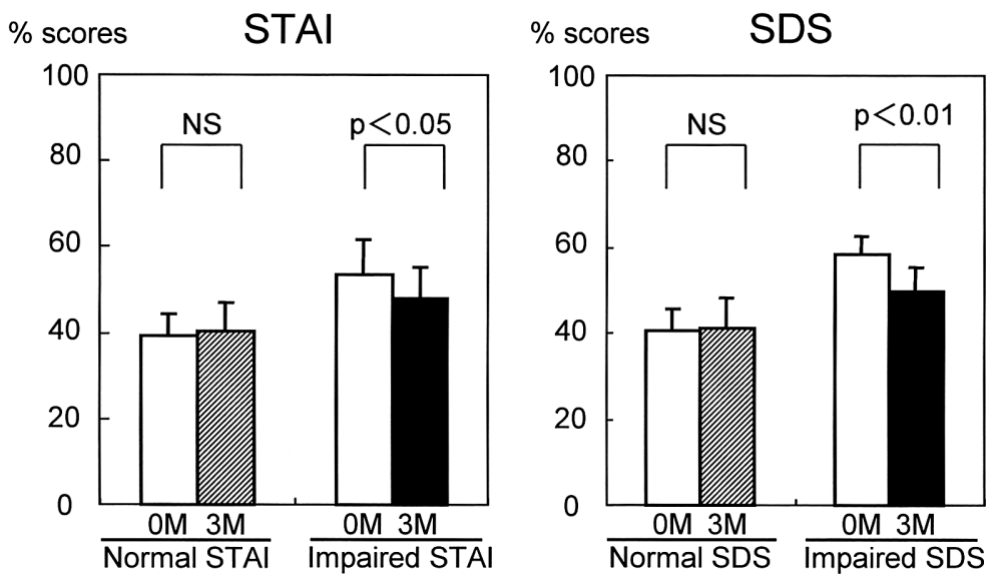

Fig 3. Changes in anxiety (STAI) and depression (SDS) scores before and after 3-month comprehensive cardiac rehabilitation (CCR) program in patients with normal and impaired mental function. Anxiety scores (STAI: State-Trait Anxiety Inventory) and depression scores (SDS: Self-rating Depression Scale) improved after CCR only in patients with impaired STAI score and impaired SDS score at baseline. OM, baseline values (before CCR); $3 \mathrm{M}$, values after 3-month CCR. ${ }^{*} \mathrm{p}<0.05$ and ${ }^{* *} \mathrm{p}<0.01$ compared with baseline values.

Table 4 Correlation Matrix of Different Types of QOL Scores

\begin{tabular}{|c|c|c|c|c|c|c|c|c|}
\hline & $\mathrm{P} \dot{V} \mathrm{O}_{2}$ & $\begin{array}{c}\dot{\mathrm{V}} \mathrm{O}_{2} \text { at } \\
\quad A T\end{array}$ & $S A S$ & $\begin{array}{l}\text { SIP } \\
\text { total }\end{array}$ & $\begin{array}{c}\text { SIP } \\
\text { physical }\end{array}$ & $\begin{array}{c}\text { SIP } \\
\text { psychosocial }\end{array}$ & STAI & $S D S$ \\
\hline$M H W-Q O L$ & 0.14 & 0.21 & $0.49 * * *$ & $0.36^{* * *}$ & $0.27 *$ & $0.38 * * *$ & $0.77^{* * * *}$ & $0.69 * * *$ \\
\hline $\mathrm{P} \dot{V} \mathrm{O}_{2}$ & & $0.74 * * *$ & $0.29 * *$ & 0.01 & 0.08 & 0.09 & 0.07 & 0.09 \\
\hline$\dot{V} O_{2}$ at $A T$ & & & $0.32 * *$ & 0.14 & 0.20 & 0.01 & 0.04 & 0.18 \\
\hline SAS & & & & $0.35 * *$ & $0.32 * *$ & $0.30 * *$ & $0.37 * * *$ & $0.43 * * *$ \\
\hline SIP total & & & & & $0.74 * * *$ & $0.81 * * *$ & $0.31 * *$ & $0.25 *$ \\
\hline SIP physical & & & & & & $0.40 * * *$ & 0.12 & 0.18 \\
\hline SIP psychosocial & & & & & & & $0.37 * * *$ & $0.28 * *$ \\
\hline STAI & & & & & & & & $0.73 * * *$ \\
\hline
\end{tabular}

Correlation coefficients and their statistical significance are presented.

Data both before and after 3-month comprehensive cardiac rehabilitation for all 44 patients were included for regression analysis. Abbreviations as in Table 2. ${ }^{*} p<0.05, * * p<0.01$, ${ }^{* * *} p<0.001$.

STAI $-10.7 \%, \mathrm{p}<0.05$; SDS $-9.8 \%, \mathrm{p}<0.05)$.

Changes in Anxiety and Depression (Fig 3)

When the patients were divided into 2 groups according to the initial STAI score $\geq$ or $<50 \%, 22$ patients $(50.0 \%)$ with STAI score $\geq 50 \%$ (ie, anxiety state) showed a significant improvement after CCR $(58.2 \pm 6.1$ to $53.0 \pm 9.3$, p $<$ $0.05)$, but the remaining 22 patients with initial STAI score $<50 \%$ (ie, normal) showed no significant change. When the patients were divided into 2 groups according to the initial SDS score $\geq$ or $<50 \%, 12$ patients (27.3\%) with SDS score $\geq 50 \%$ (ie, depressive state) showed a significant improvement in SDS score after CCR $(58.2 \pm 4.4$ to $49.7 \pm 6.4$, $\mathrm{p}<$ 0.01 ), butthe remaining 32 patients with initial SDS score $<50 \%$ (ie, normal) showed no significant change.

\section{Correlations Between MHW-QOL and Other QOL Scores (Table 4)}

The MHW-QOL score significantly correlated with SAS $(\mathrm{r}=0.49, \mathrm{p}<0.001)$ and SIP total score $(\mathrm{r}=0.36, \mathrm{p}<0.001)$, indicating that MHW-QOL represents the overall QOL of cardiac patients. Intriguingly, the MHW-QOL score correlated very tightly with the SIP psychosocial disorder score $(r=0.38, p<0.001)$, STAI $(r=0.77, p<0.001)$ and SDS $(\mathrm{r}=0.69, \mathrm{p}<0.001)$, but less tightly with the SIP physical disorder score $(r=0.27, p<0.05)$ and not significantly with $\mathrm{PVO}_{2}(\mathrm{r}=0.14, \mathrm{NS})$ or $\dot{\mathrm{VO}}_{2}$ at AT $(\mathrm{r}=0.21, \mathrm{NS})$. These findings suggest that in cardiac patients MHW-QOL mainly reflects the psychosocial and mental aspects of QOL rather than physical aspects.

\section{Discussion}

The major findings of the present study are that (1) exercise capacity and physical function-related QOL scores (ie, SAS and SIP physical disorder score) significantly improved, whereas psychosocial and mental aspect-related QOL scores (SIP psychosocial disorder score, MHW-QOL, STAI, and SDS) did not change in the whole patient group participating in the 3-month CCR program after AMI, (2) patients with impaired exercise capacity at baseline showed significant improvements in all QOL scores including both physical function-related scores and psychosocial and mental aspect-related scores, whereas patients with preserved exercise capacity showed improvements only in physical function-related QOL scores, (3) patients with anxiety or depression at baseline showed an improvement in each score after CCR, whereas those without anxiety or depression showed no change, and finally, (4) the MHW-QOL score correlated more tightly with psychosocial/mental function-related QOL scores rather than with physical function-related aspects.

\section{Previous Studies}

Many previous studies have demonstrated the benefits of CCR for QOL in patients after AMI, $,-4,6,7,20-22$ but most have used only 1 or 2 QOL instruments and assessed changes in QOL scores after CCR in the whole group. In other words, few studies have investigated which aspect of QOL (physical, psychosocial or mental aspects) is most improved by CCR, which QOL instruments are most sensitive to changes occurring during $\mathrm{CCR}$, and what type of patients obtain the 
greatest benefit from CCR after AMI. In fact, Jolliffe et al noted in their meta-analysis that it was not possible to combine the data from studies reporting health-related QOL as an outcome, because 18 different instruments were used in the 11 randomized studies reporting it as an outcome 25 Shephard et al also noted that there were few direct comparisons between different types of QOL instruments!

One direct comparisons was made by Taylor et al, who utilized 3 generic QOL instruments, including SIP, to assess changes in QOL over time in 88 patients after AMI, and found that all 3 QOL instruments had modest sensitivity. ${ }^{26}$ Smith et al ${ }^{27}$ compared 4 QOL instruments, including the Medical Outcome Study 36-item Short Form Survey $(\mathrm{SF}-36)^{28}$ in 22 cardiac patients before and after CCR, and found that only 1 of the SF-36 subscales, vitality, significantly improved over time, from which they concluded that all 4 QOL measures lacked sensitivity to change. In Japan, where most QOL questionnaires invented in Western countries and written in English cannot be directly applied to Japanese patients, comparative assessments of the different QOL instruments during CCR has not been done so far. Yoshida et al studied the MHW-QOL, STAI and SDS in patients with AMI participating in 2-week hospitalized CCR, but did not analyze correlations among the measures? Seki et al also investigated SF-36, STAI and SDS in elderly patients with coronary artery disease participating in phase III CCR, but did not analyze correlations among the measures 29 Thus, the optimal QOL test instrument or the best method of interpreting the resultant scores there has not been established!

\section{Present Study}

In the present study, we compared 5 different QOL instruments in Japanese patients participating in a 3-month CCR program with supervised exercise training and education after AMI. This enabled us to analyze which aspect of QOL improves after CCR and what type of patients gain the greatest improvement in QOL from CCR after AMI. In addition, we were able to determine the nature of the Japan-invented MHW-QOL by assessing the correlations between MHW-QOL and other established QOL scales.

\section{Improvement in QOL After CCR}

The present study has shown that $\mathrm{PVO} 2$, SAS, SIP total score and SIP physical disorder score significantly improved, whereas the SIP psychosocial disorder score, MHW-QOL, STAI, and SDS did not change in the whole patient group after CCR, which indicates that overall the physical function-related QOL scores improved, but the psychosocial and mental aspect-related QOL scores did not. Therefore, not all aspects of QOL (or all types of QOL scores) necessarily improve after CCR in patients with AMI.

Many previous studies have demonstrated an improvement in physical function-related QOL after $\mathrm{CCR}^{4,20,30-32}$ but the improvement in mental/psychosocial aspect-related QOL has been inconsistent; some studies have reported a significant improvement,20,30-33 and others have not ${ }^{34-36}$ For example, Sledge et $\mathrm{al}^{30}$ and Tyni-Lenne et $\mathrm{al}^{31}$ reported significant improvements in all areas of QOL (overall, physical, and psychosocial scores) in an 8-week CR program in cardiac patients, whereas Worcester et $\mathrm{al}^{35}$ and Daumer et $a^{36}$ reported no significant difference in the psychosocial and mental aspects of QOL between an exercise training group and a control group. Recently, Izawa et al ${ }^{37}$ using SF-36, ${ }^{28}$ reported significant improvements in the physical function-related SF-36 subscales (ie, physical functioning, role-physical, general health) but not in the mental function-related subscales (ie, social functioning, role-emotional, mental health) after CCR in patients with AMI. Thus, whether or not QOL improves after CCR in cardiac patients appears to depend on the aspect of QOL and the type of QOL instrument.

\section{Patient Characteristics Predicting Improved QOL After CCR}

In the present study, patients with impaired exercise capacity at baseline showed significant improvements in all QOL scores, including both physical function-related QOL scores and psychosocial and mental aspect-related QOL scores, whereas patients with preserved exercise capacity showed improvements only in physical function-related QOL scores. A potential explanation for this new finding is that there might be a "ceiling effect" (ie, patients with lower initial values have a greater improvement) 1 , because the low exercise capacity group in the present study tended to have worse QOL scores at the beginning of CCR (Table 3). In support of this, Lavie et al reported that elderly patients with coronary artery disease had a lower baseline $\mathrm{PVO}_{2}$ value, but a greater improvement in QOL score (SF-36), after CCR than younger patients 38 although Oldridge et al reported that higher exercise tolerance at baseline predicts a greater improvement in the quality of well-being in patients with AMI participating in CCR 39 The reason for this discrepancy is unclear, and further studies are necessary to address this issue.

The present study also demonstrated that patients with anxiety or depression at baseline showed a significant improvement in each score after CCR, whereas those without showed no change. This finding is in accordance with Oldridge et $\mathrm{al}^{39}$ who stated that a poor baseline healthrelated QOL was the predominant predictor of improved generic and specific health-related QOL after CCR. Likewise, Milani et al showed that depressed patients exhibited a greater improvement in psychosocial/mental aspect-related QOL than did normal patients.0 Again, this finding may well be explained by the ceiling effect! Taken together, the findings suggest that an improvement in QOL after CCR depends not only on the type of QOL instrument but also on the patient characteristics at baseline, and that patients with impaired QOL, anxiety, or depression at baseline should be strongly recommended to participate in CCR with an expectation of greater improvements than patients without these problems.

\section{QOL Instruments for Japanese Cardiac Patients}

Although MHW-QOL was originally invented in Japan, no study to date has systematically compared it with other established QOL instruments in patients with AMI participating in CCR. The present study has demonstrated that MHW-QOL reflects overall QOL, as indicated by a significant correlation with SIP total score, but that it mainly represents psychosocial/mental aspect-related QOL rather than physical aspect-related QOL, as indicated by the tight correlations with SIP psychosocial score, STAI and SDS (Table 4).

Recently, SF-36 (Japanese version) has become used more frequently in the field of CCR 29,37 In fact, a recent review of generic health-related QOL instruments ${ }^{41}$ suggests that the SF-36 health survey is the most commonly 
used of the generic QOL instruments reviewed ${ }^{42}$ However, some studies have raised a concern that SF-36 may not be sufficiently sensitive to measure the changes in QOL following CCR in cardiac patients? 27,43 Because a perfect QOL instrument for cardiac patients has not been established in Japan, further studies are needed to comparatively assess multiple QOL instruments and to invent a more appropriate QOL instrument for Japanese cardiac patients.

\section{Study Limitations}

First, because the present study did not have a control group not participating in CCR, it is unclear whether the improvement in QOL observed is attributable to the favorable effect of CCR or the natural course after AMI. However, the purpose of the present study was to compare different types of QOL instruments rather than to examine the efficacy of CCR on QOL in patients with AMI. To determine whether CCR improves QOL in Japanese patients after AMI, a prospective randomized study will be needed.

Second, the present study did not employ SF-36; ${ }^{25}$ however, as mentioned before, it remains unclear whether SF-36 is the most appropriate instrument to assess QOL in Japanese patients participating in CCR after AMI. Further studies are needed to directly compare the usefulness and validity of various QOL instruments, such as MHW-QOL, SIP, and SF-36, in Japanese patients participating in CCR.

Third, the present study assessed changes in QOL in a relatively short-term (ie, 3 months) CCR program. Assessment of the effects of a longer term CCR on QOL in patients with AMI may also be necessary. Finally, because the present study included only a small number of elderly (6 patients $(14 \%)>70$ years of age) and female patients (7 (16\%) female patients), the present results cannot be directly applied to such specific populations.

\section{Conclusion}

In patients with AMI, physical function-related QOL scores improve after 3-month CCR, whereas psychosocial and mental aspect-related QOL scores improve only in those with impaired exercise tolerance or impaired mental function at baseline. Thus, changes in QOL after CCR depend on the type of QOL scales and the patient's baseline status of physical and mental function. In addition, the present study demonstrated for the first time that MHW-QOL mainly reflects psychosocial/mental aspect-related QOL, as well as overall QOL, in Japanese cardiac patients.

\section{Acknowledgment}

This work was supported in part by research grants for cardiovascular disease (11C-7, 13C-3 and 15A-2) from the Ministry of Health, Labor and Welfare, Japan.

\section{References}

1. Shephard RJ, Franklin B. Changes in the quality of life: A major goal of cardiac rehabilitation. J Cardiopulm Rehabil 2001; 21: 189-200.

2. McGee HM, Hevey D, Horgan JH. Psychosocial outcome assessments for use in cardiac rehabilitation service evaluation: A 10-year systematic review. Soc Sci Med 1999; 48: 1373-1393.

3. Linden W, Stossel C, Maurice J. Psychosocial interventions for patients with coronary artery disease: A meta-analysis. Arch Intern Med 1996; 156: 745-752.

4. Dugmore LD, Tipson RJ, Phillips MH, Flint EJ, Stentiford NH, Bone MF, et al. Changes in cardiorespiratory fitness, psychological wellbeing, quality of life, and vocational status following a 12 month cardiac exercise rehabilitation programme. Heart 1999; 81: 359-366.

5. Kayaba K, Nagashima K, Saito M, Omae T, Seki A, Arakawa K, et al. The development of quality of life scales for Japanese patients with cardiovascular disease. J Jpn Assoc Cerebro-Cardiovasc Dis Cont 1990; 25: 89-96.

6. Yoshida T, Yoshida K, Yamamoto C. Effects of a two-week, hospitalized phase II cardiac rehabilitation program on physical capacity, lipid profiles and psychological variables in patients with acute myocardial infarction. Jpn Circ J 2001; 65: 87-93.

7. Fujiwara M, Asakuma S, Iwasaki T. Long-term effects of non-supervised home exercise therapy on quality of life in patients with myocardial infarction. J Cardiol 2000; 36: 213-219.

8. Otsuka Y, Takaki H, Okano Y, Satoh T, Aihara N, Matsumoto T, et al. Exercise training without ventricular remodeling in patients with moderate to severe left ventricular dysfunction early after acute myocardial infarction. Int J Cardiol 2003; 87: 237-244.

9. Sakuragi S, Takagi S, Suzuki S, Sakamaki F, Takaki H, Aihara N, et al. Patients with large myocardial infarction gain a greater improvement in exercise capacity after exercise training than those with small to medium infarction. Clin Cardiol 2003; 26: 280-286.

10. Takagi S, Sakuragi S, Baba T, Takaki H, Aihara N, Yasumura Y, et al. Predictors of left ventricular remodeling in patients with acute myocardial infarction participating in cardiac rehabilitation: Brain natriuretic peptide and anterior infarction. Circ $J$ 2004; 68: $214-$ 219.

11. Karvonen M, Kentala K, Mustala O. The effects of training on heart rate: A longitudinal study. Ann Med Exp Biol Fenn 1957; 35: $307-$ 315.

12. Fletcher GF, Balady GJ, Amsterdam EA, Chaitman B, Eckel R, Fleg $\mathrm{J}$, et al. Exercise standards for testing and training: A Statement for Healthcare Professionals From the American Heart Association. Circulation 2001; 104: 1694-1740.

13. Borg G. Perceived exertion as an indicator of somatic stress. Scand $J$ Rehabil Med 1970; 2: 92-98.

14. Uchida I, Takaki H, Kobayashi Y, Okano Y, Satoh T, Matsubara T, et al. $\mathrm{O}_{2}$ extraction during exercise determines training effect after cardiac rehabilitation in myocardial infarction. Circ J 2002; 66: 891-896.

15. Beaver WL, Wasserman K, Whipp BJ. A new method for detecting anaerobic threshold by gas exchange. J Appl Physiol 1986; 60: 2020-2027.

16. Gibbons RJ, Balady GJ, Beasley JW, Bricker JT, Duvernoy WFC, Froelicher VF, et al. ACC/AHA guidelines for exercise testing: A report of the American College of Cardiology/American Heart Association Task Force on Practice Guidelines (Committee on Exercise Testing). J Am Coll Cardiol 1997; 30: 260-315.

17. Goldman L, Hashimoto B, Cook EF, Loscalzo A. Comparative reproducibility and validity of systems for assessing cardiovascular functional class: Advantages of a new specific activity scale. Circulation 1981; 64: $1227-1234$.

18. The EPOCH Study Group. Effects of pimobendan on adverse cardiac events and physical activities in patients with mild to moderate chronic heart failure: The effects of pimobendan on chronic heart failure study (EPOCH study). Circ J 2002; 66: 149-157.

19. Gilson BS, Gilson JS, Bergner M, Bobbit RA, Kressel S, Pollard WE, et al. The sickness impact profile: Development of an outcome measure of health care. Am J Public Health 1975; 65: 1304-1310.

20. Ott CR, Sivarajan EJ, Newton KM, Bruce RA, Gilson BA. A controlled randomized study of early cardiac rehabilitation: The Sickness Impact Profile as an assessment tool. Heart Lung 1983; 12: $162-170$.

21. Loose MS, Fernhall B. Differences in quality of life among male and female cardiac rehabilitation participants. J Cardiopulm Rehabil 1995; 15: 225-231.

22. Marchionni N, Fattirolli F, Fumagalli S, Oldridge NB, Del Lungo F, Bonechi $\mathrm{F}$, et al. Determinants of exercise tolerance after acute myocardial infarction in older persons. J Am Geriatr Soc 2000; 48: $146-153$.

23. Spielberger CD, Gorsuch R, Lushene R. Manual for state-trait anxiety inventory. Palo Alto, CA: Consulting Psychologists Press, 1970.

24. Zung WW, Durham NC. A self-rating depression scale. Arch Gen Psychiatry 1965; 12: 63-70.

25. Jolliffe JA, Rees K, Taylor RS, Thompson D, Oldridge N, Ebrahim S. Exercise-based rehabilitation for coronary artery disease. Cochrane Database Syst Rev 2000; 4: CD001800.

26. Taylor R, Kirby B, Burdon D, Caves R. The assessment of recovery in patients after myocardial infarction using three generic quality-oflife measures. J Cardiopulm Rehabil 1998; 18: 139-144.

27. Smith HJ, Taylor R, Mitchell A. A comparison of four quality of life instruments in cardiac patients: SF-36, QLI, QLMI, and SEIQoL. Heart 2000; 84: 390-394 
28. Ware JE Jr, Sherbourne CD. The MOS 36-item short-form health survey (SF-36). I: Conceptual framework and item selection. Med Care 1992; 30: 473-483.

29. Seki E, Watanabe Y, Sunayama S, Iwama Y, Shimada K, Kawakami $\mathrm{K}$, et al. Effects of phase III cardiac rehabilitation programs on health-related quality of life in elderly patients with coronary artery disease: Juntendo Cardiac Rehabilitation Program (J-CARP). Circ J 2003; 67: $73-77$.

30. Sledge SB, Ragsdale K, Tabb J, Jarmukli N. Comparison of intensive outpatient cardiac rehabilitation to standard outpatient care in veterans: Effects on quality of life. J Cardiopulm Rehabil 2000; 20: 383 388.

31. Tyni-Lenne R, Gordon A, Europe E, Jansson E, Sylven C. Exercisebased rehabilitation improves skeletal muscle capacity, exercise tolerance, and quality of life in both women and men with chronic heart failure. J Card Fail 1998; 4: 9-17.

32. Stahle A, Mattsson E, Ryden L, UNden A, Nordlander R. Improved physical fitness and quality of life following training of elderly patients after acute coronary events: A 1 year follow-up randomized controlled study. Eur Heart J 1999; 20: 1475-1484.

33. Taylor CB, Houston-Miller N, Ahn DK, Haskell W, DeBusk RF. The effects of exercise training programs on psychosocial improvement in uncomplicated postmyocardial infarction patients. J Psychosom Res 1986; 30: 581-587.

34. Oldridge N, Guyatt G, Jones N, Crowe J, Singer J, Feeny D, et al Effects on quality of life with comprehensive rehabilitation after acute myocardial infarction. Am J Cardiol 1991; 67: 1084-1089.

35. Worcester MC, Hare DL, Oliver RG, Reid MA, Goble AJ. Early programmes of high and low intensity exercise and quality of life after acute myocardial infarction. BMJ 1993; 307: 1244-1247.

36. Daumer R, Miller P. Effects of cardiac rehabilitation on psychosocial functioning and life satisfaction on coronary artery disease clients. Rehabil Nurs 1992; 17: 69-72.

37. Izawa K, Hirano Y, Yamada S, Oka K, Omiya K, Iijima S. Improvement in physiological outcomes and health-related quality of life following cardiac rehabilitation in patients with acute myocardial infarction. Circ J 2004; 68: 315-320.

38. Lavie CJ, Milani RV. Disparate effects of improving aerobic exercise capacity and quality of life after cardiac rehabilitation in young and elderly coronary patients. J Cardiopulm Rehabil 2000; 20: $235-$ 240.

39. Oldridge N, Gottlieb M, Guyatt G, Jones N, Streiner D, Feeny D. Predictors of health-related quality of life with cardiac rehabilitation after acute myocardial infarction. J Cardiopulm Rehabil 1998; 18: $95-103$.

40. Milani RV, Lavie CJ, Cassidy MM. Effects of cardiac rehabilitation and exercise training programs on depression in patients after major coronary events. Am Heart J 1996; 132: 726-732.

41. Coons SF, Rao S, Keininger DL, Hays RD. A comparative review of generic quality of life instruments. Pharmacoeconomics 2000; 7: $13-35$.

42. Oldridge N. Assessing health-related quality of life: Is it important when evaluating the effectiveness of cardiac rehabilitation? J Cardiopulm Rehabil 2003; 23: 26-28.

43. Hawkes AL, Nowak M, Speare R. Short Form-36 Health Survey as an evaluation tool for cardiac rehabilitation programs: Is it appropriate? J Cardiopulm Rehabil 2003; 23: 22-25. 